\title{
Em busca de uma teoria de descentralização
}

\author{
Paulo Reis Vieira* \\ Escola Brasileira de Administração Pública e de Empresas
}

\begin{abstract}
O artigo em foco representa a síntese da tese de doutorado sob o mesmo título defendido na Universidade do Sul da Califórnia em 1967, agraciada com o prêmio Henri Reining Jr., "essência do debate centralização versus descentralização", e sendo considerada a melhor tese do ano de 1967 pela Escola de Administração Pública da referida universidade.

O tema, atualíssimo em pleno século XXI, demonstra a urgência em se buscar melhor compreensão teórico-prática entre os poucos que, no centro dos sistemas político-econômicos, podem decidir e realizar para os tantos nas periferias dos sistemas. Essa, a essência do debate centralização versus descentralização, quer em termos de países, de organizações, ou de chefes e subordinados.
\end{abstract}

A republicação do artigo contribuirá para busca de soluções mais compatíveis com os dilemas da época moderna em que a busca pela sustentabilidade permeia todos os discursos de hoje.

\section{Introdução}

Se analisasse a frequência com que se escreve e se fala sobre o problema da descentralização comprovar-se-ia, sem necessidade de recorrer a argumentos minuciosos e cuidadosamente elaborados, a oportunidade e importância da questão. A problemática do mundo contemporâneo registra, com exemplos sugestivos a serem retirados do contexto internacional ou da realidade nacional de cada país, a oportunidade do dilema centralização versus descentralização. O dilema apresenta-se microscopicamente na área da ciência política ou das relações internacionais, quando se discute a organização constitucional de nações novas, a surgirem após longos períodos de colonialismo, ou quando se procura descobrir o método mais rápido e eficaz de aceleração do processo desenvolvimentista em que se emaranham os países subdesenvolvidos à busca do desenvolvimento; ou, microscopicamente, quando se discutem na teoria administrativa estratégias, implantação, obstáculos e consequências da descentralização administrativa.

Artigo publicado na Revista de Administração Pública, Rio de Janeiro, v. 1, n. 2, p. 45-69, 1967.

* Agradecimentos: foi um privilégio inesquecível ter pertencido ao corpo docente da Ebape/FGV por quase 50 anos, desde 1955 até 2004, como professor de graduação, mestrado e doutorado. 
A controvérsia subsiste no campo da ciência política e no da administração pública. Na literatura sobre o assunto tem-se mesmo associado a descentralização ao desenvolvimento nacional em geral e ao desenvolvimento econômico, político e social, em particular. ${ }^{1}$ A descentralização político-administrativa parece tornar-se enfaticamente importante no contexto subdesenvolvido, onde a expansão rápida e urgente dos serviços públicos conduz ao crescimento paralelo das atividades governamentais. A descentralização permite aos membros de parlamentos nacionais e ao Executivo nacional cuidar melhor e com maior frequência de interesses legítimos e essencialmente nacionais, por minimizar-lhes o envolvimento com problemas locais de relevância menor. Para valorizá-lo ainda mais - e o vocábulo é usado para corresponder exatamente a um juízo de valor — , a descentralização conduz à maior participação de indivíduos, em número e intensidade, em programas e atividades governamentais, favorecendo, assim, o desenvolvimento do processo democrático. $^{2}$

Apesar da importância do problema e da pletora de material escrito sobre descentralização, tem-se estudado o fenômeno exclusivamente em dimensões doutrinárias ou valorativas, em que se prescreve a descentralização como melhor ou mais eficiente do que a centralização, sem tentar estudar-lhe os elementos componentes, ou os fatores que, de fato e não de juízo, correlacionam-se com o fenômeno. Pode-se, realmente, associar a descentralização políticoadministrativa ao processo de desenvolvimento nacional? Qual a tendência no mundo contemporâneo? Em quantos e quais países haverá maior ou menor descentralização? Pode-se, com os recursos metodológicos ao alcance dos cientistas sociais modernos, operacionalizar o fenômeno, de modo a medir diferentes graus de descentralização? Partindo da premissa básica de que o fenômeno deve correlacionar-se com algumas variáveis do ambiente nacional de cada país, como identificá-las? Sumariamente indaga-se: é possível, com base em pesquisa e análise do que ocorre em alguns países e, assim, através do raciocínio indutivo, construir-se uma teoria válida sobre descentralização?

Este trabalho propõe-se a responder a essas perguntas. Busca formular uma teoria de descentralização baseada em pesquisa empírica e, consequentemente, responder afirmativamente àquelas indagações, aceitando a premissa básica de que a distribuição de poder entre a esfera central de governo e as demais unidades inferiores em que se divide a ordem governamental transcende as situações específicas de cada nação e pode apresentar elementos comuns que devem ser investigados numa tentativa legítima de teorização.

\footnotetext{
${ }^{1}$ A ONU, através de seus organismos especializados, tem patrocinado estudos sobre o assunto. Veja-se, por exemplo, o trabalho por ela publicado Descentralization for national and local development. Nova York: United Nations ST / TAO/M/19, 1962, passim.

${ }^{2}$ Há autores que têm procurado associar descentralização, desenvolvimento e democracia. O exemplo mais específico é Henry Maddick, autor de a Democracia, descentralização e desenvolvimento. 1. ed. Rio de Janeiro: Forense, 1966.
} 


\section{Descentralização: uma construção teórica}

O fenômeno descentralização apresenta-se, sobretudo, como problema de distribuição de poder - poder de decisão e poder de ação ou execução - entre o governo central e as unidades de governo local. Esse modo de visualizar a questão dá margem, naturalmente, a certas ambiguidades e inseguranças, pois não se pode aceitar passivamente a existência real de governos locais porque alguma norma jurídica os tenha criado. Para aumentar a complexidade do problema, é preciso, ainda, ressaltar que qualquer análise das relações intergovernamentais entre o centro e as comunas ${ }^{3}$ põe de lado, em regime federativo, as unidades intermediárias de governo e de administração, o que poderá, eventualmente, ocasionar sérias distorções na realidade do fenômeno. Essas deficiências e limitações não invalidam, porém, o sistema de referência usado para, neste trabalho, proceder-se à análise da descentralização político-administrativa. Na medida em que se identifiquem os governos locais com as próprias comunidades, como se faz habitualmente ao se estudar o assunto, torna-se viável, aceitável e compreensível falar-se de poder local em contraposição a poder extralocal. Assim, justifica-se a referência ao problema da descentralização como, essencialmente, uma questão de distribuição de poder.

Para exame do assunto, considera-se a descentralização fenômeno basicamente dinâmico. Resulta desse atributo a existência de um contínuo entre dois polos extremos, o da descentralização e o da centralização, pressupondo-se, assim, a existência de graus diferentes de descentralização e a possibilidade de localização de vários sistemas político-administrativos em pontos específicos do contínuo, em função do grau de descentralização apresentado por esses sistemas.

Essa concepção de escala contínua entre dois pontos extremos ocupados por situações hipotéticas antagônicas de descentralização total versus centralização absoluta constitui o cerne da construção teórica proposta neste ensaio, pois dela decorrem outras proposições fundamentais.

Por se tratar de fenômeno que pode ocupar qualquer valor ou grandeza na escala centralização-descentralização, ${ }^{4}$ a descentralização político-administrativa não constitui conceito "puro", no sentido de que possa haver sistemas onde a variável centralização, ou a variável descentralização, seja absoluta e exclusiva. A realidade é outra. Em virtude das próprias transformações ocorrentes no contexto nacional de cada país, determinada nação pode surgir extremamente centralizada num certo momento, ou descentralizada em outro. Na verdade, os sistemas apresentam-se mistos e em movimento, fortemente caracterizados por uma combinação de elementos antagônicos, tendentes uns à centralização, conducentes outros à descentralização. Essa concepção não traz consigo a ideia de equilíbrio. Serve o propósito de justificar a noção de que o fenômeno descentralização não acontece no vácuo. Ao contrário, ocorre no contexto político. Define-se como resposta de natureza intrinsecamente política — pois o con-

\footnotetext{
${ }^{3}$ Considera-se aqui a comuna a unidade típica de governo local.

${ }^{4} \mathrm{~A}$ descentralização constitui variável contínua em contraposição à discreta.
} 
ceito de poder é crucial para sua compreensão - a determinados imperativos ambientais, os quais condicionam o funcionamento de estruturas e processos descentralizados.

\section{Descentralização e relações com o ambiente}

A descentralização político-administrativa ${ }^{5}$ depende de variáveis importantes identificáveis no contexto nacional de cada país. Não se pode, ainda, ao nível de exatidão em que se encontra a pesquisa social em nossos dias, mesmo em culturas desenvolvidas, determinarem-se relações de causa e efeito, pois estas não devem jamais confundir-se com correlações significativas testadas entre duas ou mais variáveis. Por isso mesmo, ao se afirmar que o fenômeno descentralização depende de algumas variáveis, não se está afirmando que essas variáveis causam a descentralização. O que se pode e se deve compreender é que existem correlações significativas entre a descentralização, tratada como variável dependente, e aquelas outras variáveis, isoladas ou em seu conjunto, tratadas como variáveis independentes. ${ }^{6}$

Ao se considerar a descentralização como variável dependente, é possível identificar cinco categorias de variáveis independentes que poderão manter como a primeira alguma relação, ou correlação significativa. Essas categorias intitulam-se: (a) geográficas; (b) históricas; (c) demográficas; (d) econômicas; e (e) culturais ou ecológicas.

\section{Variáveis geográficas}

As próprias características geográficas de um país devem, indubitavelmente, influenciar o grau de descentralização político-administrativa nele existente. Pode-se mesmo, em caráter experimental, imaginar que a descentralização é maior em países de grande extensão territorial. Ao se tentar estabelecer possíveis correlações entre descentralização e área surge imediatamente séria dificuldade, inerente à própria natureza das variáveis em questão. $\mathrm{O}$ fenômeno descentralização é essencialmente dinâmico, enquanto a área, basicamente estática. ${ }^{7}$ Essa diferença fundamental entre as duas variáveis pode enfraquecer qualquer correlação significativa entre elas, ou mesmo produzir a ausência total de qualquer correlação. Apesar dessas limitações, o interesse em se verificar que países, os de maior ou os de menor área, ocupam, na contínua centralização-descentralização, posições mais próximas deste último polo, não se arrefece, pelo menos para efeito de comparar sistemas políticos entre si.

\footnotetext{
${ }^{5}$ Principalmente esta seção do artigo fundamenta-se em trabalho recentemente escrito pelo autor baseado em pesquisa original sobre descentralização em 45 países e intitulado Toward a theory of descentralization: a comparative view of forty-five countries (Los Angeles, 1967).

${ }^{6}$ Entende-se por variável dependente o possível efeito e como variáveis independentes, as possíveis causas.

${ }^{7}$ Países podem anexar ou perder território. Tal somente acontece, porém, em casos esporádicos ou em ocasiões muito especiais, deixando de alterar, assim, o caráter essencialmente estático da variável.
} 
O número de unidades de governo local existentes no país constitui outro fator de natureza geográfica ${ }^{8}$ cuja relação com o fenômeno descentralização imagina-se muito significativa. ${ }^{9}$ A relação entre as duas variáveis deve ser tal que, quanto maior o número de unidades de governo local, maior também o grau de descentralização. Prevê-se, assim, relação positiva e direta entre as duas variáveis. Mais uma vez, essa possível reação padecerá das mesmas limitações e desvantagens já mencionadas no caso da extensão territorial. Justifica-se, porém, investigar o impacto do número de unidades de governo local sobre a descentralização, pelo menos para oferecer novas dimensões em que se possam alicerçar estudos comparados em ciência política e administração pública.

\section{Variáveis históricas}

Nenhum fenômeno político ou administrativo poderá escapar às influências históricas. Acredita-se serem mais descentralizados os países mais velhos. Ainda pensando em termos de história, poder-se-á testar a influência da aquisição da independência política sobre a descentralização político-administrativa. Ao conquistar ou obter sua independência, o país, se não imediatamente, pelo menos a longo prazo, organiza-se ou reorganiza-se e as questões referentes à descentralização imediatamente assumem importância vital. Embora tradição, usos e padrões coloniais não possam ser subitamente violentados e substituídos por outros, a independência significa necessariamente mudança e autonomia, indicando talvez forte tendência à descentralização.

A organização constitucional do país constitui outro elemento importante a ser examinado. Sua potencialidade como variável explicativa da descentralização político-administrativa apresenta-se ainda maior do que as demais variáveis de natureza histórica já mencionadas. Pode-se razoavelmente esperar serem mais descentralizados os sistemas federativos do que os unitários. A descentralização também se associa mais constantemente a regimes democráticos ao invés de totalitários.

Da mesma maneira, a composição populacional, caracterizada pelos elementos étnicos diversos, integrantes da população, representa outra variável relevante, cuja relação com a descentralização poderá apresentar-se significativa. Nações de composição étnica heterogênea devem ser mais descentralizadas do que onde a composição étnica é mais homogênea.

\footnotetext{
${ }^{8}$ Pode-se discutir se a variável deve classificar-se como geográfica. Por se tratar de elemento fundamentalmente estático, preferiu-se incluí-la neste grupo.

${ }^{9}$ Quando se pensa em descentralização, torna-se obrigatório imaginar que o número de unidades de governo local do sistema poderá afetar de alguma maneira a ocorrência do fenômeno. A possível correlação entre as duas variáveis deve assumir tal ordem que se torna aceitável definir o número de unidades de governo local como indicador de descentralização. Só não o fazemos porque medir descentralização em função de indicadores essencialmente descritivos e formais não conduziria à análise real do fenômeno.
} 


\section{Variáveis demográficas}

Responsabilizam-se comumente os fatores demográficos pelo desenvolvimento e crescimento dos sistemas políticos. As alterações na composição demográfica, além de sua extrema mobilidade em nossa época, afetam decisivamente os segmentos econômico, político e social das nações. Simples observação bastará ao estudioso dos fenômenos político-administrativos para verificar o impacto dos fatores demográficos junto à forma de governo, ao seu tamanho, finalidades e, até mesmo, à sua eficiência ou eficácia. Similarmente, espera-se alguma influência desses mesmos elementos demográficos sobre a descentralização.

Sugerem-se aqui variáveis importantes. A primeira refere-se à população do país em termos absolutos. Espera-se maior grau de descentralização em países de maior população. A segunda é a densidade demográfica. Imagina-se relação inversamente proporcional entre essa variável e a descentralização. O grau de urbanização apresenta-se como a terceira. Essa variável vem sendo incluída em todos os estudos mais recentes sobre a realidade políticosocial de diferentes países. ${ }^{10}$ Tem-se associado o fenômeno de urbanização ao processo de desenvolvimento econômico e ao processo de industrialização. ${ }^{11}$ Do mesmo modo, tem-se testado a interdependência da variável com o sistema educacional, o processo de desenvolvimento econômico, o sistema de comunicações, a distribuição da força de trabalho e o desenvolvimento político. ${ }^{12}$ Com base nos resultados desses trabalhos, pode-se analogicamente suspeitar que a urbanização promova a descentralização político-administrativa.

\section{Variáveis econômicas}

O fenômeno descentralização não pode escapar à influência de forças econômicas que venham condicioná-lo de algum modo. Todo sistema político compreende forças econômicas, sociais e políticas entre as quais se estabelecem relações recíprocas.

Dentre as forças econômicas atuantes sobre a descentralização, destaca-se o produto nacional bruto (PNB), por se tratar de elemento comumente empregado para indicar a riqueza e o grau de desenvolvimento econômico de um país. Pode-se, assim, esperar uma relação significativa entre o PNB e a descentralização no sentido de que, quanto maior o primeiro, maior também a última.

\footnotetext{
${ }^{10}$ Citamos três exemplos: LERNER, Daniel. The passing of the traditional society. Glencoe, III.: The Free Press, 1958; SCHNORE, Lee F. The statistical measurement of urbanization and economic development. Lond Economic, v. 38, p. 229-245, ago. 1961; LIPSET, Seymour Martin. Some social requisites of democracy: economic development and political legitimacy. American Political Science Review, v. 53, p. 69-105, mar. 1959.

${ }^{11}$ Veja-se, por exemplo, DAVIS, Kingsley; GOLDEN, Hilda. Urbanization and the development of pre-industrial areas. Economic Development and Cultural Change, n. 3, p. 6-26, out. 1954.

${ }^{12} \mathrm{O}$ trabalho de Cutright destaca-se nesse sentido. Veja-se CUTRIGHT, Phillips. National political development: measurement and analysis. American Sociological Review, v. 28, p. 253-264, abr. 1965.
} 


\section{Variáveis ecológicas}

O grupo ecológico de variáveis apresenta-se essencialmente híbrido em sua natureza. Definem-se as variáveis por exclusão. As variáveis ecológicas são as que não podem caracterizar-se fundamentalmente como geográficas, históricas, demográficas, nem econômicas.

Dentre elas ressalte-se o desenvolvimento dos canais de comunicação do sistema sob exame. Pode-se estabelecer correlação entre essa variável e a descentralização em que o maior desenvolvimento do sistema de comunicações se associe a maior grau de descentralização.

Nova visão da ecologia de um país pode ser oferecida quando se procura caracterizá-lo como predominantemente agrícola ou industrial. Espera-se serem as sociedades predominantemente agrícolas menos descentralizadas do que as sociedades industrializadas. Assim, a industrialização deve associar-se à descentralização político-administrativa, pois parece promovê-la, ao invés de obstruí-la.

Conclui-se essa tentativa de identificar variáveis relevantes para o estudo da descentralização mencionando-se, em caráter exploratório, a possibilidade de serem mais descentralizados os países onde maiores sejam os gastos com o setor público.

\section{Descentralização: testes de hipóteses}

O trabalho científico exige diálogo constante entre teoria e realidade. Temos oferecido até agora interpretação teórica sobre o fenômeno da descentralização político-administrativa baseada exclusivamente em percepções e observações pessoais. Urge, porém, testar aquelas relações sugeridas entre a descentralização e o ambiente total dentro do qual ela ocorre. Felizmente, já há evidência científica a comprovar - em alguns casos, mais, em outros, menos — a validade da teoria exploratória aqui divulgada.

Em estudo recente, em que se procedeu à macroanálise do fenômeno em 45 países diferentes, já se comprovou empiricamente a existência de correlações significativas entre a descentralização e algumas variáveis retiradas do contexto daquelas nações. ${ }^{13}$ Os países incluídos no estudo apresentavam características bem diversificadas. Foram os seguintes: Argélia, Austrália, Barbados, Bélgica, Brasil, Bulgária, Canadá, Ceilão, China Continental, Colômbia, Dinamarca, EI Salvador, Espanha, Estados Unidos, Finlândia, Gana, Guatemala, Holanda, Índia, Iraque, Irlanda, Israel, Itália, Japão, Jordânia, Marrocos, México, Noruega, Nova Zelândia, Peru, Polônia, Portugal, Porto Rico, Reino Unido, Suíça, Tanganica, Trinidad e Tobago, Venezuela, Vietnam do Sul e Iugoslávia. Foram elaboradas hipóteses entre descentralização e algumas das variáveis já mencionadas na seção anterior deste ensaio. As hipóteses foram

\footnotetext{
${ }^{13}$ O problema foi minuciosamente examinado em Vieira, Toward a theory of descentralization, op. cit., passim. Há também, sobre o mesmo assunto, o trabalho de SHERWOOD, Frank P. The correlates of descentralization: interpretations, speculations, strategies. 1967.
} 
testadas com o uso de computadores eletrônicos. A variável dependente descentralização e 10 variáveis independentes eram de natureza contínua; em dois casos empregaram-se classificações dicotômicas. O estudo de correlações múltiplas foi a técnica estatística básica.

Analisemos as hipóteses:

(1) Quanto maior a extensão territorial do país, maior o grau de descentralização nele existente: Ressalte-se ter sido a área média de 268.676 quilômetros quadrados, enquanto a amplitude da série foi de 9 milhões de quilômetros quadrados. Seis países tinham área superior a 3 milhões de quilômetros quadrados e 36 dos 45 países tinham área igual ou inferior a dez por cento (10\%) da área do maior país da série. Todos esses fatos terão, indubitavelmente, influído nos resultados obtidos.

(2) Quanto maior o número de unidades de governo local, maior o grau de descentralização.

Na distribuição da série, o número médio foi 1.015. O país com maior número de unidades de governo local foi os Estados Unidos. Trinta e três dos 36 países incluídos na série tinham dez por cento $(10 \%)$ ou menos do número de unidades de governo local existentes nos Estados Unidos. Apesar dos característicos dos dados, encontrou-se correlação significativa entre descentralização e o número de unidades de governo local no sistema.

(3) Quanto mais velho o país, maior o grau de descentralização.

A idade média dos países foi 47 anos e a amplitude da série, 186 anos. Dezessete dos 45 países tinham idade igual ou inferior a dez por cento (10\%) da idade do país mais velho. Encontrou-se correlação bastante significativa entre descentralização e idade dos países. ${ }^{14}$

(4) Países formalmente organizados em sistemas federativos são mais descentralizados que países formalmente organizados em sistemas unitários.

Não se encontrou correlação significativa entre as duas variáveis.

(5) Países heterogêneos (assim definidos em termos de sua composição étnica) são mais descentralizados do que países homogêneos.

Repetiu-se, nesse caso, a ausência de correlação significativa.

(6) Quanto maior a população, maior o grau de descentralização.

A população média foi 9.290 .000 e a amplitude um surpreendente 693.961.000, com 40 dos 45 países com população igual ou inferior a dez por cento (10\%) da população dos demais países. Mais uma vez, tais disparidades nos dados obtidos poderão ter influído na ausência de correlação encontrada entre descentralização e população.

(7) Quanto maior a densidade demográfica, menor o grau de descentralização.

A correlação encontrada entre descentralização e densidade demográfica não foi significativa. Comprovou-se, porém, o sentido inverso da correlação, conforme previsto na hipótese.

(8) Quanto maior o índice de urbanização, maior o grau de descentralização.

Encontrou-se correlação significativa entre urbanização e descentralização, embora, dentre as variáveis que mantiveram correlação significativa com a variável dependente, o fator urbanização não assumisse particular importância.

${ }^{14}$ Todas as correlações aqui citadas poderão ser verificadas na tabela 1. 
(9) Quanto maior o produto nacional bruto de uma nação, maior o grau de descentralização.

O produto nacional bruto médio dentre os países incluídos na série respectiva foi de US\$ 266.075.000. Em virtude da extrema afluência da economia dos Estados Unidos, país incluído na pesquisa, 43 das 45 nações estudadas tinham seu produto nacional bruto com o valor igual ou menor do que dez por cento (10 \%) do valor do produto nacional bruto estadunidense.

Encontrou-se correlação significativa entre o produto nacional bruto e descentralização, apesar da grande amplitude da distribuição.

(10) Quanto maior o desenvolvimento dos meios de comunicação, maior o grau de descentralização.

Mediu-se o grau de desenvolvimento dos meios de comunicação através de um índice composto de seis elementos: (a) circulação diária de jornais; (b) consumo de informações impressas per capita; (c) volume de correspondência doméstica per capita; (d) número de telefones per capita; (e) número de rádios e (f) número de aparelhos de televisão. O valor médio da série foi 27 e a amplitude, 179. O valor máximo foi obtido pelos Estados Unidos (184) e o mínimo, pela Índia (5).

Numa análise bidimensional, em que se procurou a correlação da variável dependente com cada uma das variáveis independentes, a correlação mais significativa foi obtida entre o índice de comunicações e descentralização.

(11) As nações industriais são mais descentralizadas do que as agrícolas.

Nesse caso, os países foram grupados em duas classes: 11 foram considerados industriais e 34 agrícolas. Verificou-se correlação bastante significativa entre a natureza do país, se predominantemente agrícola ou industrial, e o grau de descentralização alcançado.

(12) Quanto maior a percentagem dos gastos no setor público, maior o grau de descentralização.

Nenhuma correlação significativa foi encontrada ao testar-se essa hipótese.

\section{Descentralização: tentativa de mensuração}

Em busca de uma teoria válida sobre descentralização, surge como primeiro obstáculo o da operacionalização do conceito. A grande dificuldade da pesquisa social no momento reside exatamente na enorme complexidade inerente a qualquer esforço destinado à mensuração ou quantificação do fenômeno social. Apesar de já se vislumbrarem em certos meios alguns exageros nessa tentativa de quantificação, só se conseguirá maior exatidão na pesquisa social com o aperfeiçoamento de processos e instrumentos de mensuração dos fenômenos sociais.

Qualquer definição operacional de descentralização apresentará sempre sérias limitações, em virtude da grande complexidade do problema. Haverá dois grandes grupos de definições. Às primeiras chamamos de formais e, às segundas, de comportamentalistas. As definições formais incluem elementos retirados de constituições escritas, estatutos ou leis, 
em que se define a descentralização como o processo legal de investir de autoridade também legal e formal algumas estruturas políticas e administrativas locais, com o fim de permitir-lhes formular diretrizes básicas, consubstanciadas na política local, e executar serviços públicos locais. Esse grupo de definições se caracteriza por sua natureza essencialmente formalística. ${ }^{15}$ Como exemplos de definições formais estão as que se baseiam no número de unidades locais para indicar a existência de descentralização no sistema, ou na relação entre esse número e a área total do país, com o mesmo propósito. As definições comportamentalistas oferecem visão mais realista do fenômeno, pois, ao invés de fixarem-se em elementos nitidamente formais, procurarão, no sistema, elementos que possam indicar, de forma mais exata, o aspecto predominantemente dinâmico da descentralização.

O índice de descentralização usado na pesquisa que oferece as informações necessárias para este ensaio fundamenta-se na premissa básica de que descentralizar resume-se essencialmente em distribuir poder. Descentralização é distribuição de poder entre várias esferas de governo. Medi-la, portanto, significa, de certo modo, medir também o poder. Embora parcial, é aceitável o critério de investigar-se a extensão do poder de uma unidade de governo e, assim, a sua capacidade de decidir e agir, em função dos recursos financeiros de que poderá dispor. Conclui-se, portanto, que um índice de descentralização pode ser elaborado com informações sobre receitas e despesas referentes aos governos locais. ${ }^{16}$

Mediu-se a descentralização nos 45 países em função de dois critérios básicos: (a) medida da proporção entre a receita total obtida pelos governos locais em cada país e a receita obtida pelo governo central e (b) medida da proporção entre a despesa total realizada pelas unidades de governo local e a despesa total realizada pelo governo central. O índice foi construído sob a proposição básica de que, quanto maiores fossem aquelas proporções, maior o grau de descentralização existente no país. Usando fórmulas para maior esclarecimento, teremos:

$\mathrm{D}=\mathrm{g} / \mathrm{G}$

$\mathrm{D}==\mathrm{r} / \mathrm{R}$

onde D é descentralização; $\mathbf{r}$ representa o total anual da receita obtida pelos governos locais no país; $\mathbf{R}$ representa o total anual da receita obtida pelo governo central; $\mathbf{g}$ significa a despesa total anual realizada pelos governos locais e $\mathbf{G}$ a despesa anual total realizada pelo governo central.

\footnotetext{
${ }^{15} \mathrm{O}$ conceito de formalismo foi introduzido na literatura por Fred W. Riggs. Vejam-se duas de suas obras: Administration in developing countries, the theory of prismatic society. Boston: Houghton Mifflin Company, 1964 e A ecologia da administração pública. Rio de Janeiro: Fundação Getulio Vargas, 1965.

${ }^{16} \mathrm{O}$ assunto foi exaustivamente debatido, com suas vantagens e desvantagens, em Vieira, Toward a theory of descentralization, op. cit., capítulo III.
} 
Tabela 1

Matriz das correlações entre as medidas nacionais de descentralização e 12 variáveis independentes

\begin{tabular}{|c|c|c|c|c|c|c|c|c|c|c|c|c|c|c|}
\hline & & 1 & 2 & 3 & 4 & 5 & 6 & 7 & 8 & 9 & 10 & 11 & 12 & 13 \\
\hline 1. & População & - & & & & & & & & & & & & \\
\hline 2. & Densidade demográfica & 0,01 & - & & & & & & & & & & & \\
\hline 3. & Área & 0,55 & 0,28 & - & & & & & & & & & & \\
\hline 4. & Idade & 0,05 & 0,00 & 0,13 & - & & & & & & & & & \\
\hline 5. & PNB & 0,26 & 0,08 & 0,49 & 0,32 & - & & & & & & & & \\
\hline 6. & Urbanização & 0,76 & 0,03 & 0,61 & 0,26 & 0,74 & - & & & & & & & \\
\hline 7. & Comunicações & 0,08 & 0,04 & 0,37 & 0,40 & 0,55 & 0,30 & - & & & & & & \\
\hline 8. & $\begin{array}{l}\text { Número de unidades de } \\
\text { governo local }\end{array}$ & 0,17 & 0,07 & 0,42 & 0,36 & 0,98 & 0,71 & 0,54 & - & & & & & \\
\hline 9. & Gastos no setor público & 0,23 & 0,07 & 0,06 & 0,08 & 0,11 & 0,09 & 0,18 & 0,11 & - & & & & \\
\hline 10. & $\begin{array}{l}\text { Natureza dos países } \\
\text { (agrícola } \times \text { industrial) }\end{array}$ & 0,07 & 0,12 & 0,23 & 0,38 & 0,33 & 0,15 & 0,83 & 0,31 & 0,19 & - & & & \\
\hline 11. & $\begin{array}{l}\text { Organização } \\
\text { constitucional }\end{array}$ & 0,19 & 0,21 & 0,58 & 0,19 & 0,32 & 0,34 & 0,38 & 0,30 & 0,03 & 0,23 & - & & \\
\hline & Composição étnica & 0,33 & 0,40 & 0,22 & 0,28 & 0,21 & 0,40 & 0,11 & 0,19 & 0,02 & 0,12 & 0,21 & - & \\
\hline & Descentralização & 0,11 & 0,01 & 0,11 & 0,35 & 0,28 & 0,25 & 0,65 & 0,29 & 0,15 & 0,54 & 0,04 & 0,02 & - \\
\hline
\end{tabular}

Fonte: Reprodução de Vieira (1967).

Assim, pode-se medir a descentralização em bases anuais, mediante o exame de orçamentos nacionais ou outros dados agregativos publicados pelos diversos países. As fórmulas vistas indicam com suficiente clareza que, quanto maiores forem o $\mathbf{g}$ em relação ao $\mathbf{G}$ e o $\mathbf{r}$ em relação ao $\mathbf{R}$, maior será o grau de descentralização no sistema. Imaginando-se, a seguir, cada país como uma unidade ou 1, pelo emprego das fórmulas (1) e (2), pode-se idealizar uma situação de absoluta, perfeita e ideal centralização em que:

$1-\mathrm{g} / \mathrm{G}=1$

e $1-r / R=1$

em que se verificaria a inexistência de qualquer forma de governo local, pois a descentralização não existiria. De fato, nesse caso, $\mathrm{D}=\mathrm{g}=\mathrm{O}$ ou $\mathrm{D}=\mathrm{r}=\mathrm{O}$.

Similarmente, pode-se visualizar a situação contrária, de descentralização total, absoluta e perfeita em que:

$1-\mathrm{g} / \mathrm{G}=\mathrm{O}$

e $1-r / R=O$ 
Nesse caso, $\mathrm{D}=\mathrm{g}=\mathrm{G}=1$ e $\mathrm{D}=\mathrm{r}=\mathrm{R}=1$. Em tal hipótese, uma situação estranha e bastante curiosa apareceria, pois a receita e a despesa realizadas pelos governos locais se igualariam à receita e despesa realizadas pelos governos centrais e o próprio conceito de descentralização teria de desaparecer exatamente quando o grau de descentralização viesse a alcançar seu máximo valor.

Usando-se a definição operacional de descentralização (1), torna-se possível identificar os dois pontos extremos (3) e (5) do contínuo no qual cada país poderá ser localizado desde o ponto zero (centralização perfeita) até o ponto igual a 1, que corresponderia a situações em que existisse descentralização perfeita ou absoluta. Os pontos extremos do contínuo são úteis no sentido em que enriquecem o modelo teórico aqui elaborado. ${ }^{17}$ Numa atitude realista, espera-se, porém, que todos os países ocupem posições intermediárias entre os dois polos do contínuo.

\section{Descentralização: uma teoria à guisa de conclusão}

O problema da descentralização político-administrativa continua a desafiar a argúcia e a criatividade de cientistas sociais. Em primeiro lugar, há uma questão de nomenclatura. Pensa-se, quase sempre, em termos da dicotomia centralização-descentralização ao invés de atentar-se para a contínua centralização versus descentralização. No cerne de todos os debates sobre o tema, surge frequentemente a necessidade de definir o papel da descentralização como força propulsora do desenvolvimento nacional, pois não raro se considera a descentralização melhor e mais eficiente do que a centralização.

A teoria exploratória divulgada neste ensaio reveste-se essencialmente de características políticas. O enfoque é menos doutrinário ou administrativo. Resulta de macroanálise do problema e se confirma como válido através do exame de informações colhidas para 45 países diferentes.

A descentralização influencia e é influenciada pelo ambiente. O emprego da técnica estatística de correlação múltipla permitiu alcançar números que mostram que as 12 variáveis independentes, agindo simultaneamente, podem explicar cerca de sessenta por cento (60\%) da variação total nos graus de descentralização existentes nos 45 países. Cada uma das variáveis independentes afeta a descentralização de modo diverso. Encontraram-se correlações significativas entre descentralização e comunicações, natureza e idade dos países, número de unidades de governo local, produto nacional bruto e, em intensidade menor, urbanização. Nenhuma correlação significativa parece ocorrer entre descentralização e área do país, sua organização constitucional, a heterogeneidade de sua população, o número de seus habitantes, sua densidade demográfica e a grandeza dos gastos no setor público.

\footnotetext{
${ }^{17}$ Teoricamente outras situações poderiam ocorrer pois as fórmulas $1-\mathrm{g} / \mathrm{G}=\infty$ e $1-\mathrm{r} / R=8$ podem ser elaboradas. Veja-se Vieira, Toward a theory of descentralization, op. cit., p. 140.
} 
O exame da matriz de correlações revela as forças do ambiente tendentes a estimular a descentralização. Vejamos alguns exemplos:

a) A idade do país apresenta correlações significativas com sete variáveis independentes: produto nacional bruto, urbanização, comunicações, número de unidades de governo local, natureza do país (agrícola $\times$ industrial), composição étnica e população.

b) O produto nacional bruto correlaciona-se significativamente com oito variáveis independentes: urbanização, comunicações, número de unidades de governo local, natureza do país (agrícola $\times$ industrial), população, área, idade e organização constitucional.

c) A urbanização correlaciona-se significativamente com sete variáveis independentes: população, área, idade, produto nacional bruto, número de unidades de governo local, composição étnica e organização constitucional.

d) O nível de comunicações correlaciona-se significativamente com sete variáveis independentes: área, idade, produto nacional bruto, urbanização, número de unidades de governo local, natureza do país (agrícola $\times$ industrial) e a organização constitucional.

e) O número de unidades de governo local apresenta correlações significativas com sete variáveis independentes: área, idade, produto nacional bruto, urbanização, comunicações, natureza do país (agrícola $\times$ industrial) e organização constitucional.

Essas relações recíprocas entre todas as variáveis apontam como válida a proposição fundamental de que a descentralização não ocorre no vácuo, mas em arena povoada por inúmeras forças dentre as quais já podemos destacar as variáveis acima. Assim, se, no panorama da administração municipal brasileira, o estado de São Paulo destaca-se dentre os demais, não o será, talvez, por simples acaso. Muito significativo o fato de que esse estado apresenta o maior índice de industrialização do país, o maior índice de urbanização, tirante o caso especial da Guanabara, possui uma história de luta constante por governos independentes ou autônomos, é um dos maiores contribuintes para a riqueza nacional, ocupa o segundo lugar dentre os 22 estados da federação no referente ao número de unidades de governo local e possui, inegavelmente, o melhor sistema de comunicações do país. ${ }^{18}$

A teoria de descentralização elaborada aqui apresenta as seguintes características principais: a) há forças, no contexto de cada país, que decisivamente funcionam como elementos propulsores da descentralização; b) o grau de descentralização alcançado por um país parece depender principalmente de forças econômico-tecnológicas; c) os elementos culturais, as características e a organização constitucional do país não parecem exercer impacto decisivo no fenômeno descentralização.

As correlações de maior significação foram encontradas entre a descentralização e as variáveis de natureza econômico-tecnológicas, como o desenvolvimento dos canais de comunicação, a natureza industrial do país e o produto nacional bruto.

\footnotetext{
${ }^{18}$ Sherwood, The correlates of descentralization, op. cit., p. 21.
} 
De maior interesse foi a correlação encontrada entre descentralização e os canais de comunicações. De todas as correlações será essa a que melhor corresponderá à realidade, pois a distribuição dos dados sobre as comunicações foi a que mais se aproximou, dentre as demais séries, da distribuição normal. Esse resultado pode sugerir estratégias e suscitar muitas discussões. Inegavelmente, se a descentralização político-administrativa significa maior envolvimento e se maior participação exige comunicação ampla e abrangente, pode-se prever que o desenvolvimento dos canais de comunicação do país se transforme em condição indispensável à maior descentralização. Resultam, assim, algumas definições de estratégia. Se realmente a descentralização se associa ao processo de desenvolvimento nacional, principalmente no que se refere ao desenvolvimento econômico, pois a descentralização se correlaciona significativamente com variáveis de natureza econômica, devem-se estimular fórmulas e estruturas descentralizadas nos países em desenvolvimento, para acelerar-se o processo desenvolvimentista. Tais propósitos serão alcançados através do desenvolvimento do sistema de comunicações que, por sua vez, poderá ser conseguido através de atividades específicas na área de educação.

\section{Conclusões finais}

O cientista social moderno enfrenta o grave desafio de ter de buscar correlações significativas entre variáveis integrantes do contexto social. Indaga-se se são possíveis, ao nível atual de desenvolvimento das ciências sociais, tentativas de pesquisas empíricas em que se busquem comprovar correlações entre variáveis econômicas, políticas e sociais. Um dos objetivos deste ensaio constituiu-se em oferecer um exemplo de como, mediante a utilização de dados agregativos, apesar de sérias limitações, é viável operacionalizar conceitos, medir, embora parcialmente, fenômenos sociais e extrair desses esforços novas hipóteses conducentes a melhor explicação da realidade.

Procurou-se, ainda, examinar o fenômeno descentralização como uma resposta de natureza intrinsecamente política a certos imperativos do ambiente. O exame da questão ofereceu evidência de que a descentralização político-administrativa poderá ser objeto de novas investigações em que se focalizem variáveis fundamentalmente econômicas ou outras diretamente relacionadas com o sistema de comunicações, ao invés de se enfatizarem elementos mais fáceis de serem pesquisados, como a população ou a densidade demográfica.

Finalmente, pretende-se oferecer aqui subsídios para estudos na área de administração comparada. Assim, o fecho mais apropriado às ideias aqui apresentadas, que foram propositadas e basicamente menos conclusivas do que provocadoras, será a visão de como diferem alguns países em graus de descentralização. Responde-se, assim, à pergunta: quais os países mais descentralizados no contexto internacional? Faz-se através da seguinte tabela. ${ }^{19}$

\footnotetext{
${ }^{19}$ Obtiveram-se os graus de descentralização mediante a soma de pontos que cada país obtinha ao localizar-se na contínua centralização-descentralização, de maneira que se atribuíssem pontos maiores aos países que ocupassem posições mais próximas do polo da descentralização. No período de 1950 a 1964, cada país teve seu grau de descentralização computado 16 vezes, em anos diferentes, com base na definição operacional de descentralização, já explicada neste trabalho.
} 
Tabela 2

Graus de descentralização

\begin{tabular}{|c|c|c|}
\hline Ordem & País & Graus de descentralização \\
\hline 1 & Suécia & 111 \\
\hline 2 & Noruega & 85 \\
\hline 3 & Reino Unido & 81 \\
\hline 4 & Suíça & 78 \\
\hline 5 & Estados Unidos & 73 \\
\hline 6 & Dinamarca & 68 \\
\hline 7 & lugoslávia & 66 \\
\hline 8 & China Continental & 62 \\
\hline 9 & Nova Zelândia & 61 \\
\hline 10 & Argélia & 57 \\
\hline 11 & Bélgica & 55 \\
\hline 12 & Holanda & 55 \\
\hline 13 & Colômbia & 53 \\
\hline 14 & Irlanda & 50 \\
\hline 15 & Canadá & 48 \\
\hline 16 & Itália & 47 \\
\hline 17 & Polônia & 44 \\
\hline 18 & Portugal & 41 \\
\hline 19 & Japão & 40 \\
\hline 20 & Espanha & 34 \\
\hline 21 & Brasil & 33 \\
\hline 22 & Bulgária & 30 \\
\hline 23 & Síria & 30 \\
\hline 24 & Jordânia & 29 \\
\hline 25 & Romênia & 28 \\
\hline 26 & Tanganica & 28 \\
\hline 27 & Iraque & 25 \\
\hline 28 & Porto Rico & 24 \\
\hline 29 & Gana & 22 \\
\hline 30 & Israel & 21 \\
\hline 31 & Barbados & 18 \\
\hline 32 & Guatemala & 17 \\
\hline 33 & Austrália & 16 \\
\hline 34 & Ceilão & 16 \\
\hline 35 & El Salvador & 16 \\
\hline 36 & Finlândia & 16 \\
\hline 37 & Índia & 16 \\
\hline 38 & Marrocos & 16 \\
\hline 39 & México & 16 \\
\hline 40 & Peru & 16 \\
\hline 41 & República Árabe Unida & 16 \\
\hline 42 & República Dominicana & 16 \\
\hline 43 & Trinidad e Tobago & 16 \\
\hline 44 & Venezuela & 16 \\
\hline 45 & Vietnam do Sul & 16 \\
\hline
\end{tabular}

Fonte: Reprodução de Vieira (1967). 


\section{Summary}

Toward a theory of decentralization: a comparative view on forty-five countries

Decentralization is a very complex, challenging, and fundamental phenomenon. It has been studied primarily on doctrinal and valuational bases. This study, of an empirical crossnational nature, aims at building an embryonic theory by identifying which major variables from the countries' environments are closely associated with decentralization, which is treated as a dependent variable.

Theoretical Framework. Decentralization is visualized as essentially a question of distribution of power and as a dynamic, rather than a static, phenomenon. This implies the existence of a continuum between the poles of centralization and decentralization and presupposes the idea of degrees of decentralization, according to which countries may be located along the continuum. Furthermore, decentralization is assumed to occur in a political setting; and it is the political response to certain environmental imperatives that condition the operation of decentralized structures and processes.

Hypotheses. The general hypothesis is that a feedback process exists between decentralization and its total environment. Operational hypotheses tested were: (1) the greater area of a country, the higher the degree of decentralization; (2) the greater the number of local units, the greater the degree of decentralization; (3) the older the country, the higher the degree of decentralization; (4) the federal are more decentralized than nonfederal countries; (5) countries with heterogeneous, rather than homogenous, ethnic populations are more decentralized; (6) the greater the population, the higher the degree of descentralization; (7) the greater the population density, the lower the degree of decentralization; (8) the greater the gross national product, the higher the degree of decentralization; (9) the greater the development of mass media communications, the higher the degree of decentralization; (10) the more urbanized countries are more decentralized; (11) industrial countries are more decentralized; and (12) countries that spend more in public services are more descentralized.

Methodology. Problems of availability of aggregate data primarily determined the size and selection of the sample. Similarly, an index of decentralization was built by contrasting local to national revenues and expenditures for a given number of years in each country involved. Scatter diagrams were elaborated to illustrate the types of relationships between decentralization and independent variables. A multiple correlation technique provided the basic statistical treatment for the data.

Findings. The multiple correlation analysis provided statistical support for the general hypothesis that an interrelationship exists between the environment and the decentralization level of a country. Correlations, at a level of statistical significance, were found between decentralization and communications, age and nature of countries, number of local units, gross 
national product, and urbanization, thus providing support for hypotheses 2, 3, 8, 9, 10 and 11. There did not seem to be a particular relationship between decentralization and the area of the country, the federal system, the heterogeneity of the population, the size of the population, the density of the population, or the amount of money spent on public services.

Conclusions. The principal argument of the study, viz. that decentralization is essentially a political response to environmental imperatives, is sufficiently supported by the data to suggest more profound analyses of the way in which power distribution becomes institutionalized in a variety of settings. Also, the findings suggest that certain elements in the environment, such as economic level, may provide more fruitful avenues of inquiry than the more familiar considerations, such as area and density of population. However, there are many methodological problems to be resolved in such macroanalytic studies. Problems of criteria for measuring decentralization levels and the collection and publication of data on a uniform basis seem particularly crucial.

\section{À guisa de reformulação}

A questão em foco do artigo se apresenta, hoje, como fundamental em busca de soluções para o homem e de seu bem-estar em sociedades nacionais ou internacionais. A aflição humana é visível em busca de padrões mais solidários de convivência em que os mais bem aquinhoados possam contribuir para o bem-estar de excluídos de melhores oportunidades. Nisso reside a atualidade da discussão que constitui a essência do artigo. Apenas os dados quantitativos seriam diferentes se viessem a ser replicados. (Paulo Reis Vieira)

Paulo Reis Vieira foi professor da Escola Brasileira de Administração Pública e de Empresas (Ebape/FGV) nos cursos de graduação, mestrado e doutorado no período de 1955 a 2004. E-mail: paulo.vieira@fgv.br. 
